\title{
АНТИТЕРРОРИСТИЧЕСКИЕ НОРМЫ УК РФ И ПРАКТИКА ИХ ПРИМЕНЕНИЯ
}

\section{С.М. Кочои}

Московский государственный юридический университет им. О.Е. Кутафина (МГЮА), г. Москва, Российская Федерация

\author{
Инбормация о статье \\ Дата поступления \\ 10 марта 2017 г. \\ Дата принятия в печать \\ 6 апреля 2018 г. \\ Дата онлайн-размещения \\ 27 апреля 2018 г.
}

\section{Ключевые слова}

Терроризм; антитеррористические нормы; преступления террористической направленности; преступления террористического характера; квалификация преступлений; совокупность преступлений

\section{Финансирование}

Государственное задание

на выполнение НИР в рамках базовой части проекта № 29.4916.2017/8.9

«Уголовно-правовая политика противодействия терроризму: генезис, состояние и перспективы»

\begin{abstract}
Аннотация. Уголовно-правовые нормы, предусматривающие ответственность за террористические преступления, или антитеррористические нормы УК РФ, постоянно совершенствуются. В последний раз изменениям и дополнениям они подверглись 6 июля 2016 г. (федеральный закон № 375-ФЗ). Некоторые из этих законодательных новелл вызывают в литературе справедливую критику, однако, по признанию многих, есть и такие новеллы, обоснованность (добавим, и криминологическая обусловленность) которых бесспорна. Вопросы противодействия терроризму находятся в поле зрения не только законодателя, но и правоприменителя. Последний в лице Пленума Верховного Суда РФ 9 февраля 2012 г. принял постановление № 1 «О некоторых вопросах судебной практики по уголовным делам о преступлениях террористической направленности», а уже 3 ноября 2016 г. внес в него существенные изменения и дополнения (постановление № 41). Безусловно, частые и быстрые изменения законодательства, а также рекомендаций высшей судебной инстанции по их применению отражаются на качестве правоприменительной деятельности. В частности, обращают на себя внимание низкий процент раскрываемости дел о терроризме (особенно на территории субъекта РФ, где совершается большинство преступлений террористической направленности, - в Республике Дагестан) и наличие множества спорных вопросов квалификации таких преступлений. По итогам проведенного исследования сделан вывод о том, что к наиболее сложным вопросам применения антитеррористических норм УК РФ следует относить установление целей совершения террористического акта (ст. 205), а также правомерность квалификации террористического акта по совокупности с другими преступлениями (предусмотренными, в частности, ст. 105, 205.4, 205.5, 208, 209, 210 и др.). Сформулированы предложения и рекомендации, предусматривающие возможность корректировки текущей судебной практики.
\end{abstract}

\section{ANTITERRORISM NORMS IN THE CRIMINAL CODE OF THE RUSSIAN FEDERATION AND THE PRACTICE OF THEIR ENFORCEMENT}

Samvel M. Kochoi

Kutafin Moscow State Law University (MSAL), Moscow, the Russian Federation

Article info
Received
2017 March 10
Accepted
2018 April 6
Available online
2018 April 27
Keywords
Terrorism; antiterrorism norms; crimes
of terrorism; qualification of crimes;
aggregate of crimes

Abstract. The criminal law norms that regulate liability for terrorism crimes, or antiterrorism norms of the Criminal Code of the Russian Federation, are being constantly improved. They were last changed and amended on July 6, 2016 (Federal Law № 375$\Phi 3)$. Some of these novels are justly criticized by scholars but, as many admit, there are novels whose validity (and criminological causation) is beyond doubt. The issues of counteracting terrorism are on the radar of not only the lawmakers, but also the law enforcement bodies. The latter, represented by the Plenary Session of the Supreme Court of the Russian Federation of February 9, 2012, adopted the Decree No 1 «On Some Issues of Court Practice on Criminal Cases of Terrorism Crimes»; already on November 3, 2016 it introduced considerable changes and amendments to it (Decree No 41). Undoubtedly, frequent and quick changes in legislation, as well as the recommendations of the highest judicial authority on their use, influence the quality of the law enforcement work. Particular attention is attracted by a low clearance rate for cases of terrorism (especially in the region of Russia where a large number of terrorism crimes is committed - in the Republic of Dagestan) and the multitude of disputable points regarding the characteriza- 


\section{Acknowledgements}

State task for research within the basic part of the Project № 29.4916.2017/8.9 "Criminal Law Policy of Counteracting Terrorism: Genesis, Condition and Prospects» tion of such crimes. The conducted research allows the author to conclude that the most complicated issues of using the antiterrorism norms of the Criminal Code of the Russian Federation include the determination of the goals of an act of terrorism (Art. 205) and the legitimacy of defining a terrorism act cumulatively with other crimes (under, in particular, Art. 105, 205.4, 205.5, 208, 209, 210 and others). The author also formulates suggestions and recommendations for the correction of the current judicial practice.
В науке существует множество классификаций терроризма. Согласно одной из них, следует выделять внешний терроризм и внутренний («домашний») [1] терроризм. Очевидно, в настоящее время наибольшую опасность представляет внешний (международный) терроризм, при этом одна из международных террористических организаций - «Исламское государство» (далее $-И Г)^{1}-$ представляет глобальную угрозу для всей современной цивилизации.

Деятельность террористических организаций, согласно обновленной Стратегии национальной безопасности РФ, относится к «основным угрозам государственной и общественной безопасности»². По заявлению президента РФ, за десять лет в мире совершено более 100 тыс. террористических актов, их жертвами стали люди самых разных национальностей и вероисповедания. Например, только в 2014 г. от рук террористических группировок погибло свыше 32 тыс. чел. из 67 стран мира 3 .

По замечанию зарубежных исследователей, террористические акты 11 сентября 2001 г. привели к росту расходов на научные исследования проблем борьбы с терроризмом, итоги которых подчеркивают необходимость продолжения усилий по стимулированию новых исследований и оценки эффективности принимаемых мер в сфере борьбы с терроризмом [2]. Правда, и здесь не обходится безе перекосов. Отмечается, что у исследователей больший интерес вызывают террористические атаки, чем сами террористические организации, причины их возникновения, активности и упадка [3]. В этой связи нельзя не отметить, что свой серьезный вклад в активизацию террористической деятельности вносят также те россияне, которые присягнули на верность ИГ.

${ }^{1}$ О признании международных организаций террористическими и запрете их деятельности на территории РФ [Электронный ресурс] : решение Верхов. Суда РФ от 29 дек. 2014 г. по делу № АКПИ14-1424С // СПС «КонсультантПлюс».

2 О Стратегии национальной безопасности Российской Федерации : указ Президента РФ от 31 дек. 2015 г. № 683. URL: http://static.kremlin.ru/media/events/files/ru/pdf.

${ }^{3}$ Вручение верительных грамот Президенту России. URL: http://kremlin.ru/events/president/news/50786.
Так, согласно данным ГРУ Генштаба и ФСБ, только в Сирии на стороне ИГ воюют «до четырех тысяч боевиков из России и тысяч пять - из республик бывшего Советского Союза»".

В самой России, как следует из официальной статистики Генеральной прокуратуры РФ, в 2016 г. зарегистрировано 2214 преступлений террористического характера. Из них 1487 приходится на пять северокавказских субъектов РФ - Дагестан, Ингушетию, Чечню, КабардиноБалкарию и Карачаево-Черкесскую Республику. При этом следует иметь в виду низкий показатель раскрываемости таких преступлений. Так, из 996 преступлений, зарегистрированных на территории Республики Дагестан, не раскрыто 603. В целом же по России прирост зарегистрированных преступлений террористического характера в 2016 г. составил 44,6\%5.

Вместе с тем следует иметь в виду ту неразбериху с терминологией, которая присутствует в официальной статистике. Так, на сайте Генеральной прокуратуры РФ утверждается, что статистика зарегистрированных «преступлений террористического характера» отражает количество «преступлений террористической направленности» ${ }^{6}$. И далее перечисляются следующие виды «преступлений террористической направленности»:

- террористический акт;

- вовлечение в совершение преступлений террористического характера или иное содействие их совершению;

- публичные призывы к осуществлению террористической деятельности или публичное оправдание терроризма;

$$
\text { - захват заложников; }
$$

${ }^{4}$ Путин назвал число воюющих на стороне боевиков в Сирии россиян // PИA Новости. URL: https://ria.ru/ syria/20170223/1488675479.html.

5 Показатели преступности России // Портал правовой статистики. URL: http://crimestat.ru/offenses_rate.

${ }^{6}$ Форма статистического наблюдения «Сведения о состоянии преступности и результатах расследования преступлений», утвержденная приказом Росстата от 13 октября 2009 г. № 222, предоставляемая информационными центрами МВД, ГУВД, УВД субъектов РФ (URL: http://crimestat.ru/offenses_rate). 
- заведомо ложное сообщение об акте терроризма;

- организация незаконного вооруженного формирования или участие в нем.

Таким образом, в цитируемом документе о преступлениях «террористической направленности» и «террористического характера» говорится как о равнозначных понятиях. При этом понятие «преступления террористической направленности» встречается также в разъяснениях Пленума Верховного Суда РФ - в постановлении «О некоторых вопросах судебной практики по уголовным делам о преступлениях террористической направленности» от 9 февраля 2012 г. № 1. Хотя здесь Пленум и не раскрывает содержание названного понятия, но поясняет, что постановление посвящено практике применения ст. 205, 205.1, 205.2 и 208 УК РФ (3 ноября 2016 г. данный перечень был дополнен преступлениями, предусмотренными ст. 205.3, 205.4 и 205.5 УК РФ). Из этого заявления, очевидно, вытекает, что именно указанную выше совокупность и следует считать «преступлениями террористической направленности».

Однако здесь необходимо напомнить, что УК РФ не использует понятия «преступления террористической направленности» и «преступления террористического характера». Отсутствуют они также в Федеральном законе «О противодействии терроризму» от 6 марта 2006 г. № 35-Ф3. В этой связи нельзя согласиться с утверждением о том, что в данном федеральном законе дается перечень преступлений террористической направленности [4], поскольку оба закона (УК РФ и ФЗ № 35-ФЗ) используют другой термин - «террористическая деятельность». Однако и в последнем случае нет единства в том, что касается его содержания. Если, например, в Федеральном законе «О противодействии терроризму» понятие «террористическая деятельность» у́же, чем «преступления террористической направленности» («преступления террористического характера»), то в УК РФ понятие «террористическая деятельность» либо шире, как, например, в ст. 205.1, либо у́же, как в ст. 205.3 и 205.4.

Очевидно, что настало время унифицировать используемую на практике (а перед этим в законодательстве) терминологию. Терроризм, как отмечают в зарубежной криминологии, это «идеологически мотивированное насилие» [5]. Исходя из такого понимания терроризма, полагаем возможным вводить в научный оборот тер- мин «террористические преступления». Однако вместо того чтобы давать легальное определение данного термина, считаем целесообразным закрепить непосредственно в тексте закона исчерпывающий перечень террористических преступлений [6].

Помимо изложенного, следует подчеркнуть, что в корректировке нуждается не только терминология в тексте закона, но также практика применения данного закона.

Вопросы практики применения антитеррористических норм УК РФ рассматриваются в постановлении Пленума Верховного Суда РФ «О некоторых вопросах судебной практики по уголовным делам о преступлениях террористической направленности» от 9 февраля 2012 г. № 1. Из его названия следует, что оно посвящено категории преступлений (преступлений «террористической направленности»), формально отсутствующей в профильном федеральном законе и УК РФ. Поэтому рассматриваемое постановление правильнее было бы называть «О некоторых вопросах судебной практики по уголовным делам о террористической деятельности».

В новой редакции данного постановления (от 3 ноября 2016 г.) впервые обращено внимание на важность установления целей террористического акта (именно целей, а не цели, как ошибочно заявляют отдельные ученые [7, с. 541; 8]). Действительно, как показывают материалы изученных нами уголовных дел, суды не уделяют должного внимания обоснованию, в частности, обязательного (и столь важного) признака, предусмотренного ст. 205 УК РФ, как цель воздействия на принятие решения органами власти (или международными организациями).

Например, в соответствии с определением Северо-Кавказского окружного военного суда У. в составе организованной группы совершил приготовление к террористическому акту путем взрыва «в целях воздействия на принятие решений органами власти». Однако террористический акт не смог совершить, поскольку был ликвидирован сотрудниками правоохранительных органов.

Х., отец обвиняемого, в апелляционной жалобе высказал несогласие с определением военного суда и просил отменить его. По утверждению Х., доказательств вины его сына в совершении преступления, предусмотренного ч. 1 ст. 30, п. «а» ч. 2 ст. 205 УК РФ (в редакции федерального закона от 27 декабря 2009 г. № 377Ф3), в деле не было установлено. Взрывчатое вещество планировалось использовать против 
сотрудников правоохранительных органов, т.е. действия, совершенные У., имели своей целью «воспрепятствование их законной деятельности по охране общественного порядка и обеспечению общественной безопасности».

Судебная коллегия Верховного Суда отклонила указанные доводы, не попытавшись при этом доказать наличие в действиях У. цели воздействия на принятие решений органами власти ${ }^{7}$.

Другим наглядным примером может служить кассационное определение Верховного Суда РФ по делу Л., К. и других лиц, осужденных в 2006 г. Верховным Судом Республики Дагестан за группу преступлений, в том числе за преступление, предусмотренное ч. 1 ст. 205 УК РФ. В своей жалобе Л. указывал, что Верховный Суд Республики Дагестан, нарушив постановление Пленума Верховного Суда РФ от 9 февраля 2012 г., в приговоре не выяснил, «с какой целью совершались террористические акты». По этой причине просил приговор изменить и признать незаконным осуждение его по ч. 1 ст. 205 УК РФ. Однако и в данном случае Верховный Суд РФ, оставив без удовлетворения жалобу осужденного, не стал обосновывать наличие в его действиях цели террористического акта ${ }^{8}$.

По изученным нами опубликованным делам о террористическом акте (ст. 205 УК РФ) только в материалах нескольких (из 150) дел суды обосновали цель оказания воздействия на органы власти. Так, в приговоре по делу А. было сказано, что он решил создать организованную группу для совершения террористических актов «в целях воздействия на принятие решений органами власти Российской Федерации об изменении внутренней национальной политики в интересах истинных представителей русского народа, по ужесточению миграционной политики ${ }^{9}$. В материалах еще одного дела суд пояснил, что осужденные объединились в группу именно с целью совершения преступления подрыва железнодорожного состава, изгото-

7 Апелляционное определение Верховного Суда РФ от 22 сентября 2015 г. № 205-АПУ15-6 [Электронный ресурс] // СПС «КонсультантПлюс».

8 Кассационное определение Верховного Суда РФ от 5 марта 2015 г. № 20-015-1сп [Электронный ресурс] // Там же.

9 Постановление Президиума Верховного Суда РФ от 11 декабря 2013 г. № 237-П12пр [Электронный ресурс] // СПС «КонсультантПлюс» ; Кассационное определение Верховного Суда РФ от 2 августа 2011 г. № 23-011-9 [Электронный ресурс] // Там же. вили взрывное устройство и осуществили его закладку для подрыва железнодорожного состава, перевозящего нефтепродукты, «с целью воспрепятствования их вывоза из <... Республики, т.е. с целью оказания воздействия на органы власти и прекращения вывоза нефти ${ }^{10}$.

Представляется, что практику таких судов (раскрывающих цели преступления) следует поддержать. По крайней мере, в таком случае она не будет вызывать принципиальных споров относительно законности и обоснованности предъявляемого виновному (виновным) обвинения в совершении террористического акта, в составе которого признак цели, как уже было отмечено, занимает одно из центральных мест. В первую очередь это касается случаев, когда обвиняемый утверждает, что убийство сотрудника правоохранительного органа или военнослужащего совершено с целью воспрепятствования их законной деятельности, которая, как известно, является обязательным признаком другого преступления - предусмотренного ст. 317 УК РФ (согласно данным статистики, убийств при совершении данного преступлении совершается больше, чем при совершении террористического акта [9]).

Кроме изложенного, нельзя не отметить спорную рекомендацию Пленума Верховного Суда РФ относительно целей террористического акта и их установления. Так, в п. 1 рассматриваемого постановления смешаны разные признаки: вина, цели и мотивы преступления ${ }^{11}$.

10 Кассационное определение Верховного Суда РФ от 12 декабря 2012 г. № 23-012-17 [Электронный ресурс] // СПС «КонсультантПлюс».

${ }^{11}$ Пункт 1 постановления Пленума Верховного Суда РФ «О некоторых вопросах судебной практики по уголовным делам о преступлениях террористической направленности» гласит: «Обратить внимание судов на то, что цели дестабилизации деятельности органов власти или международных организаций либо воздействия на принятие ими решений являются обязательным признаком террористического акта (статья 205 УК РФ).

При решении вопроса о направленности умысла виновного лица на дестабилизацию деятельности органов власти или международных организаций следует исходить из совокупности всех обстоятельств содеянного и учитывать, в частности, время, место, способ, обстановку, орудия и средства совершения преступления, характер и размер наступивших или предполагаемых последствий, а также предшествующее преступлению и последующее поведение виновного.

О цели оказания воздействия на принятие решений органами власти или международными организациями может свидетельствовать побуждение соответствующих субъектов к совершению определенных действий либо к воздержанию от их совершения, содержание требова- 
В этой связи предлагаем следующую его редакцию: «Обратить внимание судов на то, что цели дестабилизации деятельности органов власти или международных организаций либо воздействия на принятие ими решений являются обязательным признаком террористического акта (статья 205 УК РФ).

При решении вопроса о наличии указанных целей следует исходить из совокупности всех обстоятельств содеянного и учитывать, в частности, время, место, способ, обстановку, орудия и средства совершения преступления, характер и размер наступивших или предполагаемых последствий, предшествующее преступлению и последующее поведение виновного».

Еще одна проблема касается случаев квалификации по совокупности террористического акта и других преступлений. Так, по мнению Пленума Верховного Суда РФ, в случаях, когда последствием совершения террористического акта является умышленное причинение смерти человеку (в том числе двум или более лицам), содеянное охватывается полностью п. «б» ч. 3 ст. 205 УК РФ, дополнительная квалификация по ст. 105 УК РФ при этом не нужна ${ }^{12}$. Наряду с этим высшая судебная инстанция предлагает действия виновного лица квалифицировать по совокупности преступлений, предусмотренных ст. 205 УК РФ и, соответственно, ст. 220, 221, 222, 222.1, 223, 223.1 или 226 УК РФ, в случаях, когда во время совершения террористического акта использованы незаконно приобретенные либо хранящиеся ядерные материалы и радиоактивные вещества, а также незаконно приобретенные, хранящиеся либо изготовленные огнестрельное оружие, боеприпасы, взрывчатые вещества или взрывные устройства.

Данная рекомендация, по нашему мнению, игнорирует санкцию ч. 3 ст. 205 УК РФ, которая между тем достаточно строгая, чтобы не учитывать общественную опасность преступлений, предусмотренных ст. 220, 221, 222, 222.1, 223,

ний участников преступления» (См.: О некоторых вопросах судебной практики по уголовным делам о преступлениях террористической направленности : постановление Пленума Верхов. Суда РФ от 9 февр. 2012 г. № 1 : (ред. от 3 нояб. 2016 г.) // СПС «КонсультантПлюс»).

12 Интересно, что Конституционный Суд РФ отказал в принятии к рассмотрению жалобы на приговор, согласно которому покушение на убийство "не охватывается» составом террористического акта, предусмотренного п. «б» ч. 3 ст. 205 УК РФ. См.: Определение Конституционного Суда РФ от 29 января 2015 г. № 153О [Электронный ресурс] // СПС «КонсультантПлюс»
223.1 и 226 УК РФ. Более того, она настолько строгая, что превосходит санкцию даже нормы об убийстве, в результате чего, по мнению Пленума Верховного Суда РФ (но не отдельных ученых [10-13]), отпадает необходимость в квалификации террористического акта и убийства по совокупности. Поэтому и квалификация теракта по совокупности с преступлениями, предусмотренными ст. 220, 221, 222, 222.1, 223, 223.1 и 226 УК РФ, представляется избыточной.

Еще одна серьезная проблема, встречающаяся на практике, связана с возможной квалификацией по совокупности преступлений, предусмотренных ст. 205 и 208, 209 или 210 УК РФ. Так, Верховный Суд РФ не поддержал содержащийся в кассационном представлении прокурора вывод о том, что А., Д. и Л. действовали в составе банды. Согласно позиции Верховного Суда РФ, совершенный ими взрыв в кафе «с целью причинить значительный ущерб его владельцам уроженцам Кавказа, устрашить местное население, дестабилизировать обстановку в обществе и тем самым вынудить органы власти ужесточить миграционную политику», обоснованно квалифицирован нижестоящим судом как террористический акт, предусмотренный пп. «а» и «в» ч. 2 ст. 205 УК РФ, который дополнительной квалификации по ст. 209 УК РФ не требует ${ }^{13}$.

В кассационной жалобе по делу А., осужденного по нескольким статьям, включая ст. 205, 208 и 209 УК РФ, адвокат утверждал, что «осуждение по ст. 208 ч. 2 УК РФ является излишним, поскольку поглощается ч. 2 ст. 209 УК РФ» ${ }^{14}$. В принципе, если исходить из позиции отдельных ученых, то в ситуации, подобной этой, речь должна идти о реальной совокупности преступлений, так как «одна и та же криминальная структура не может признаваться одновременно и бандой, и НВФ» [14]. Однако Верховный Суд РФ в приведенном примере занял иную позицию, не согласившись с доводами автора жалобы ${ }^{15}$.

Чтобы понять сложности практики применения уголовно-правовых норм о групповом со-

\footnotetext{
${ }^{13}$ Кассационное определение Верховного Суда РФ от 20 сентября 2012 г. № 209-012-5 [Электронный ресурс] // СПС «КонсультантПлюс».

${ }^{14}$ Определение Верховного Суда РФ от 17 января 2007 г. по делу № 23-006-69 [Электронный ресурс] // Там же.

${ }^{15}$ Как отмечают в литературе, «отдельно уголовноправовая норма об организации незаконного вооруженного формирования или участии в нем применяется редко». Чаще она применяется с другими статьями, в частности ст. 205, 206, 209 [15].
} 
вершении террористического акта, необходимо выяснить, что суды вкладывают в содержание понятий «организованная группа», «незаконное вооруженное формирование», «банда», «преступное сообщество». Так, в отдельных приговорах банды признаются структурными подразделениями преступного сообщества или даже частью «международной преступной организации» (или «международной террористической организации»), вовсе не известной УК РФ. В другом случае из приговоров следует, что незаконные вооруженные формирования могут создавать банды (под общим названием «джамматы»), в третьем - подобные «джамматы» называются не бандой, а структурными подразделениями преступного сообщества, и т.д.

Учитываются ли все эти особенности правоприменительной практики в рекомендациях Пленума Верховного Суда РФ? Представляется, что не в полной мере. Так, в соответствии с анализируемым постановлением Пленума Верховного Суда РФ (п. 13) действия участников террористического сообщества, террористической организации, незаконного вооруженного формирования, совершивших террористический акт, должны квалифицироваться по правилам о совокупности преступлений, ответственность за совершение которых предусмотрена ст. 205 и 205.4, 205.5 или 208 УК РФ.

Такого же характера рекомендации содержатся в пп. 28 и 29 данного постановления:

- в случае совершения участником незаконного вооруженного формирования конкретного преступления террористической направленности его действия будут квалифицироваться по совокупности преступлений, ответственность за совершение которых предусмотрена ч. 2 ст. 208 УК РФ, и соответствующей статьей УК РФ: 205, 205.1, 205.2, 206 и др.;

- в случае если члены незаконных вооруженных формирований объединились в устойчивую вооруженную группу (банду) в целях нападения на граждан или организации либо в террористическое сообщество, руководят такой группой (бандой) или террористическим сообществом, а также участвуют в совершаемых ими нападениях или преступлениях террористической направленности, содеянное такими лицами подлежит квалификации по совокупности преступлений, предусмотренных ст. 208 и 209 или 205.4 УК РФ.

Однако, во-первых, если террористический акт, повлекший убийство, не рекомендуется ква- лифицировать по совокупности, то в чем логика квалификации террористического акта по совокупности с другими, объективно менее опасными преступлениями?

Во-вторых, при таких рекомендациях стирается грань между различными видами криминальных объединений: организованной группой при террористическом акте (ст. 205 УК РФ), террористическим сообществом (ст. 205.4 УК РФ), террористической организацией (ст. 205.5 УК РФ), незаконным вооруженным формированием (ст. 208 УК РФ), бандой (ст. 209 УК РФ) и преступным сообществом (преступной организацией) (ст. 210 УК РФ). Подобные рекомендации исключают, в частности, возможность трансформации незаконного вооруженного формирования или банды в более опасные криминальные объединения - террористическое сообщество и террористическую организацию, что вряд ли оправданно [16].

Складывающаяся судебно-следственная практика подтверждает вывод о том, что целью создания террористических сообществ является совершение именно террористических актов. «Так, целями террористических сообществ в Северо-Кавказском федеральном округе и ряде других регионов страны (в частности, в Республике Татарстан) являются ведение силовых методов борьбы (джихада), установление радикальной формы ислама и создание исламского государства в Российской Федерации» [17 $]^{16}$.

Как нам представляется, в случае совершения террористическим сообществом, террористической организацией, бандой, незаконным вооруженным формированием или преступным сообществом (преступной организацией) террористического акта вменение признака «террористический акт, совершенный организованной группой» должно исключаться, поскольку все перечисленные объединения представляют собой разновидности организованной группы или преступного сообщества (преступной организации).

По данному вопросу в литературе высказано мнение о том, что при квалификации отдельных преступлений по совокупности с преступлением, ответственность за совершение которого предусмотрена ст. 205.4 УК РФ, необходимо учитывать то обстоятельство, что «особый мотив и организованность поведения субъектов являются квалифицирующими признаками

${ }^{16}$ О попытках использования террористами радикальной формы ислама см.: [18; 19]. 
ряда преступлений». Исходя из этого делается вывод о том, что совершение преступления организованной группой в случаях, когда создание данной группы или участие в ней уже содержит самостоятельный состав преступления, «должно квалифицироваться с учетом признака организованности независимо от того, что создание или участие в организованной группе вменяется в качестве самостоятельного состава» [20].

Однако, с нашей точки зрения, данное предложение нельзя считать приемлемым, поскольку признак «совершение преступления организованной группой» в таком случае фактически будет учитываться дважды.

Таким образом, в желании ужесточить ответственность за террористические преступления Пленум Верховного Суда РФ пошел по пути дачи рекомендаций, позволяющих одни и те же действия квалифицировать, по сути, повторно - как террористический акт, совершенный одновременно организованной группой, незаконным вооруженным формированием, бандой или даже преступным сообществом (преступной организацией). Причем остается без внимания то обстоятельство, что квалификация указанных действий по одной лишь статье 205 УК РФ позволяет применить к террористу фактически одну из самых строгих в отечественном уголовном законодательстве санкций. По приведенным выше причинам практику квалификации одних и тех же действий одновременно по ряду статей УК РФ следует признать не только избыточной, но и лишенной практического смысла.

\section{СПИСОК ИСПОЛЬЗОВАННОЙ ЛИТЕРАТУРЫ}

1. Gruenewald J. A Comparison of Ideologically-Motivated Homicides from the New Extremist Crime Database and Homicides from the Supplementary Homicide Reports Using Multiple Imputation by Chained Equations to Handle Missing Values / J. Gruenewald, W.A. Pridemore // Journal of Quantitative Criminology. - 2012. - Vol. 28, iss.1. - P. 141-162.

2. Lum C. Are counter-terrorism strategies effective? The results of the Campbell systematic review on counter-terrorism evaluation research / C. Lum, L. W. Kennedy, A. Sherley // Journal of Experimental Criminology. - 2006. - Vol. 2, iss. 4. - P. 489-516.

3. Miller E. Patterns of Onset and Decline Among Terrorist Organizations / E. Miller // Journal of Quantitative Criminology. 2012. - Vol. 28, iss. 1. - P. 77-101.

4. Маршакова Н.Н. Преступления террористической направленности в системе уголовного законодательства: теоретическое исследование / Н.Н. Маршакова // Российский следователь. - 2015. - № 24. - С. 34-39.

5. Investigating the Applicability of Macro-Level Criminology Theory to Terrorism: A County-Level Analysis / J.D. Freilich [et al.] // Journal of Quantitative Criminology. - 2015. - Vol. 31, iss. 3. - P. 383-411.

6. Кочои С.М. Общеевропейское законодательство о борьбе с терроризмом и перспективы реформирования УК РФ / C.M. Кочои // Lex Russica. - 2014. - № 9. - С. 1061-1069.

7. Комментарий к Уголовному кодексу Российской Федерации / отв. ред. А.И. Рарог. - 10-е изд. - М. : Проспект, 2014. -960 c.

8. Комментарий к Уголовному кодексу Российской Федерации (постатейный) / под ред. Г.А. Есакова. - 7-е изд., перераб. и доп. - М. : Проспект, 2017. - 736 с.

9. Корецкий Д.А. Гомицид: преступления, связанные с убийством / Д.А. Корецкий, Е.С. Стешич // Уголовное право. 2016. - № 1. - С. 93-98.

10. Иногамова-Хегай Л.В. Концептуальные основы конкуренции уголовно-правовых норм / Л.В. Иногамова-Хегай. М. : Норма, 2015. - 288 c.

11. Габдрахманов Р.Л. Квалификация террористического акта по УК РФ / Р.Л. Габдрахманов // Российский следователь. -2015 . - № 4. - С. 16-20.

12. Ростокинский А.В. Очередные «антитеррористические» новеллы или введение в «уникальную» часть Уголовного кодекса? / А.В. Ростокинский, К.А. Толпекин // Российский следователь. - 2014. - № 18. - С. 31-34.

13. Гладких В.И. Парадоксы современного законотворчества: критические заметки на полях Уголовного кодекса / В.И. Гладких // Российский следователь. - 2012. - № 11. - С. 15-18.

14. Меркурьев В.В. Проблемы квалификации деятельности участников террористических групп и сообществ в СевероКавказском регионе / В.В. Меркурьев, П.В. Агапов // Российский следователь. - 2013. - № 20. - С. 14-18.

15. Мусаелян М.Ф. Проблемы уголовно-правовой квалификации и отграничения террористического акта от захвата заложника, организации незаконного вооруженного формирования или участия в нем, бандитизма, нападения на лиц или учреждения, которые пользуются международной защитой / М.Ф. Мусаелян // Комментарий судебной практики. 2010. - Вып. 15. - С. 211-228.

16. Антонова Е.Ю. Преступления террористического характера и экстремистской направленности: вопросы криминализации и пенализации / Е.Ю. Антонова // Российский следователь. - 2016. - № 13. - С. 21-25.

17. Агапов П.В. Организация террористического сообщества и участие в нем: проблемы криминализации и правоприменения / П.В. Агапов // Российская юстиция. - 2015. - № 7. - С. 23-25.

18. Sentas V. Policing the Diaspora: Kurdish Londoners, MI5 and the Proscription of Terrorist Organizations in the United Kingdom / V. Sentas // The British Journal of Criminology. - 2016. - Vol. 56 (5). - P. 898-918.

19. Greer S. Anti-Terrorist Laws and the United Kingdom's 'Suspect Muslim Community': A Reply to Pantazis and Pemberton / S. Greer // The British Journal of Criminology. - 2010. - Vol. 50 (6). - P. 1171-1190. 
20. Комментарий к Уголовному кодексу Российской Федерации (постатейный) : в 2 т. / под ред. А.В. Бриллиантова. 2-е изд. - М. : Проспект, 2015. - Т. 2. - 704 с.

\section{REFERENCES}

1. Gruenewald J.A., Pridemore W.A. Comparison of Ideologically-Motivated Homicides from the New Extremist Crime Database and Homicides from the Supplementary Homicide Reports Using Multiple Imputation by Chained Equations to Handle Missing Values. Journal of Quantitative Criminology, 2012, vol. 28, iss.1, pp. 141-162.

2. Lum C., Kennedy L.W., Sherley A. Are counter-terrorism strategies effective? The results of the Campbell systematic review on counter-terrorism evaluation research. Journal of Experimental Criminology, 2006, vol. 2, iss. 4, pp. 489-516.

3. Miller E. Patterns of Onset and Decline Among Terrorist Organizations. Journal of Quantitative Criminology, 2012, vol. 28, iss. 1 , pp. $77-101$.

4. Marshakova N.N. Terrorism-related crimes in the system of criminal laws: theoretical study. Rossiiskii sledovatel' $=$ Russian Investigator, 2015, no. 24, pp. 34-39. (In Russian).

5. Freilich J.D., Adamczyk A., Chermak S.M., Boyd K.A., Parkin W.S. Investigating the Applicability of Macro-Level Criminology Theory to Terrorism: A County-Level Analysis. Journal of Quantitative Criminology, 2015, vol. 31, iss. 3, pp. 383-411.

6. Kochoi S.M. All-European antiterrorist legislation and prospects of reforming Criminal Code of the Russian Federation. Lex Russica, 2014, no. 9, pp. 1061-1069. (In Russian).

7. Rarog A.I. (ed.). Kommentarii k Ugolovnomu kodeksu Rossiiskoi Federatsii [Comments to the Criminal Code of the Russian Federation]. 10 $0^{\text {th }}$ ed. Moscow, Prospekt Publ., 2014. 960 p.

8. Esakov G.A. (ed.). Kommentarii k Ugolovnomu kodeksu Rossiiskoi Federatsii (postateinyi) [Comments to the Criminal Code of the Russian Federation (article-by-article)]. $7^{\text {th }}$ ed. Moscow, Prospekt Publ., 2017. 736 p.

9. Koretskii D.A., Steshich E.S. Homicide: Murder-Related Crimes. Ugolovnoe pravo = Criminal Law, 2016, no. 1, pp. 93-98. (In Russian).

10. Inogamova-Khegai L.V. Kontseptual'nye osnovy konkurentsii ugolovno-pravovykh norm [Conceptual Basis of Criminal Law Norms' Competition]. Moscow, Norma Publ., 2015. 288 p.

11. Gabdrakhmanov R.L. Qualification of terrorist act under the Criminal Code of the RF. Rossiiskii sledovatel' $=$ Russian $^{2}$ Investigator, 2015, no. 4, pp. 16-20. (In Russian).

12. Rostokinskii A.V., Tolpekin K.A. The latest «anti-terrorist» innovations or introduction to a «unique» part of the Criminal Code? Rossiiskii sledovatel' = Russian Investigator, 2014, no. 18, pp. 31-34. (In Russian).

13. Gladkikh V.I. Paradoxes of contemporary law-making: critical notes on the margins of the Criminal Code. Rossiiskii sledovatel' = Russian Investigator, 2012, no. 11, pp. 15-18. (In Russian).

14. Merkur'ev V.V., Agapov P.V. Problems of training participants of terrorist groups and communities in the North Caucasus region. Rossiiskii sledovatel' = Russian Investigator, 2013, no. 20, pp. 14-18. (In Russian).

15. Musaelian M.F. Problems of criminal law qualification and differentiation between a terrorist act and taking a hostage, the organization of an illegal armed band or a participation in it, banditry, attack of persons or agencies under international protection. Kommentarii sudebnoi praktiki = Comments to Court Practice, 2010, iss. 15, pp. 211-228. (In Russian).

16. Antonova E.Yu. Crimes of terroristic character and extremist orientation: issues of criminalization and penalization. Rossiiskii sledovatel' = Russian Investigator, 2016, no. 13, pp. 21-25. (In Russian).

17. Agapov P.V. The organization of the terrorist community and participation: problems of criminalization and enforcement. Rossiiskaya yustitsiya = Russian Justice, 2015, no. 7, pp. 23-25. (In Russian).

18. Sentas V. Policing the Diaspora: Kurdish Londoners, MI5 and the Proscription of Terrorist Organizations in the United Kingdom. The British Journal of Criminology, 2016, vol. 56 (5), pp. 898-918.

19. Greer S. Anti-Terrorist Laws and the United Kingdom's 'Suspect Muslim Community': A Reply to Pantazis and Pemberton. The British Journal of Criminology, 2010, vol. 50 (6), pp. 1171-1190.

20. Brilliantov A.V. (ed.). Kommentarii k Ugolovnomu kodeksu Rossiiskoi Federatsii (postateinyi) [Comments to the Criminal Code of the Russian Federation (article-by-article)]. $2^{\text {nd }}$ ed. Moscow, Prospekt Publ., 2015. Vol. 2. 704 p.

\section{ИНФОРМАЦИЯ ОБ АВТОРЕ}

Кочои Самвел Мамадович - профессор кафедры уголовного права Московского государственного юридического университета им. О.Е. Кутафина (МГЮА), доктор юридических наук, профессор, заслуженный работник высшей школы Российской Федерации, почетный работник юстиции России, г. Москва, Российская Федерация; еmail:sam.kochoi@bk.ru.

\section{ДЛЯ ЦИТИРОВАНИЯ}

Кочои С.М. Антитеррористические нормы УК РФ и практика их применения / С.М. Кочои // Всероссийский криминологический журнал. - 2018. - Т. 12, № 2. C. 258-265. - DOI: 10.17150/2500-4255.2018.12(2).258265.

\section{INFORMATION ABOUT THE AUTHOR}

Kochoi, Samvel V. - Professor, Chair of Criminal Law, Kutafin Moscow State Law University (MSAL), Doctor of Law, Professor, Honorary Worker of Russian Higher Education, Honorary Worker of Russian Justice, Moscow, the Russian Federation; e-mail: sam.kochoi@bk.ru.

\section{FOR CITATION}

Kochoi S.V. Antiterrorism norms in the Criminal Code of the Russian Federation and the practice of their enforcement. Vserossiiskii kriminologicheskii zhurnal $=$ Russian Journal of Criminology, 2018, vol. 12, no. 2, pp. 258-265. DOI: 10.17150/2500-4255.2018.12(2).258-265. (In Russian). 